FREUd, S. (1905) On Psychotherapy. Reprinted (1953-1974) in The Standard Edition of the Complete Psychological Works of Sigmund Freud (trans. and ed. J. Strachey). vol. 7. pp. 257-268. London: Hogarth Press.

GARNER, J. (1997a) Dementua: an Intimate death: anticipatory or current grief? British Journal of Medical Psychology, 70, 177-184.

- (1997b) Freud and old age: psychoanalytic aspects of ageing. Old Age Psychiatrist. 8. 4.

- (1998) Open letter to the Director General of Fair Trading. APP Newsletter, 22, 4-5.

- \& Evans. S. (1996) Psychodynamic perspectives in old age psychiatry: a necessary integration. (APP Conference Report). Psychiatric Bulletin. 20. 111.

- \& ARDERN. M. (1998) Reflections on old age. Aging and Mental Health, 2, 92-93.

Grant, S.. Holmes, J. \& Watson, J. (1993) Guidelines for psychotherapy training as part of general professional psychiatric training. Psychiatric Bulletin. 17. 695-698.

HILDEBRAND. P. (1982) Psychotherapy with older patients British Journal of Psychological Medicine, 55, 19-28.

HUNTER, A. J. G. (1989) Reflections on psychotherapy with ageing people individually and in groups. British Journal of Psychiatry. 154, 250-252.

JACQUES. E. (1965) Death and the mid-life crisis. International Journal of Psychoanalysis, 46. 502-514.

KING. P. (1980) The life cycle as indicated by the nature of the transference in the psychoanalysis of the middleaged and elderly. International Journal of Psychoanalysis, 61, 153-160.

KITwOoD, T. (1990) The dialectics of dementia: with particular reference to Alzheimer's disease. Ageing and Soclety. 10, 177-196.

MARTINDALE, B. (1989) Becoming dependent again: the fears of some elderly patients and their younger therapists. Psychoanalytic Psychotherapy. 4, 67-75.
MEERLOO, J. A. M. (1955) Psychotherapy with elderly people. Geriatrics, 10. 583-587.

O'CONNOR. D. (1993) The impact of dementia: a self psychological perspective. Journal of Gerontological Social Work, 20, 113-128.

PORTER. R. (1996) The psychoanalytic psychotherapist and the old age psychiatry team. In Psychiatry in the Elderly (2nd edn) (eds R. Jacoby \& C. Oppenheimer). pp. 251268. Oxford: Oxford University Press.

ROTH. A. D. \& FONAGY. P. (1996) Psychotherapy: What Works for Whom? New York: Guilford Press.

SchmiD, A. H. (1990) Dementia, related disorders and old age: psychodynamic dimensions in diagnosis and treatment. American Journal of Psychoanalysis, 50. 253-262.

SEGAL. H. (1958) Fear of death: notes on the analysis of an old man. International Journal of Psychoanalysis, 39. 173-181.

Sinason V. (1992) Mental Handicap and the Human Condition. New Approaches from the Tavistock. London: Free Association Books.

STORR. A. (1960) Torture without violence. New Statesman. 12 March. 358.

TERRY, P. (1997) Counselling the Elderly and their Carers. Basingstoke: Macmillan.

WILLAMMS, D. \& GaRNER, J. (1998) Affective memory in dementia. British Journal of Psychiatry. 172. 379-380.

WinNicoTt. D. W. (1971) Playing and Reality. London: Tavistock.

ZiviAn, M. T., LARSEN, W., Knox, V. J., et al (1992) Psychotherapy for the elderly: psychotherapists preferences. Psychotherapy, 29, 668-674.

Jane Garner, Consultant Psychiatrist, Department of Old Age Psychiatry. Chase Farm Hospital, The Ridgeway. Enfield, Middlesex EN2 8JL

\title{
Disruption of children's lives by maternal psychiatric admission
}

\author{
Valerie Hawes and David Cottrell
}

\begin{abstract}
Aims and method The aim of the study was to investigate changes in child care arrangements after admission of mothers to acute psychiatric wards. Data were collected by interview where possible and from case notes.

Results Twelve out of 53 children of mothers interviewed had to move house. Chronicity of psychiatric disorder was evident in half the mothers. Clinical implications Children's lives are affected by maternal psychiatric admission with the likelihood of repeated disruption where psychiatric disorder is chronic.
\end{abstract}

Over the past five decades there has been considerable research, both epidemiological and clinical, which described the consequences for children of parental psychiatric disorder. Much of this research has been reviewed and its practical applications discussed in Gopfert et al (1996). However, it seems that such knowledge has had relatively little impact on the psychiatric care of patients who are also mothers. In the context of risk assessment of mothers, Oates (1997) has pointed out that there are no questions relating to child care in the Health of the Nation Outcome Scale. 
While the evidence from both epidemiological and clinical research suggests that problems for children are related to various aspects of the parent-child relationship and the effect on this of parental psychiatric disorder, little attention has been paid to more practical consequences for children. These may include separation from mother, change of carer and moving house if a psychiatrically-ill mother is admitted to hospital, with multiplication of this disruption if there are repeated admissions.

\section{The study}

The aim of the present study was to investigate changes in child care arrangements in a consecutive series of mothers admitted to acute psychiatric wards of two east London boroughs. Information about whether female in-patients were mothers of children aged 16 years or less was obtained by regular contacts with nursing staff on the wards concerned. Where suitable subjects were identified and willing to participate, a short semi-structured interview was conducted on the ward. This covered demographic data about mothers and children, with information about child care arrangements. Brief details of diagnosis, length of admission and past psychiatric history were recorded from case notes later. Twenty-six mothers were interviewed and these subjects are referred to as the interview group:

At an early stage of the study, it became clear that it was not possible to interview some potential subjects because of language difficulty or their disturbed mental state, and that some would be discharged before interview could be arranged. It was decided to record basic demographic and psychiatric data from case notes for the 25 others in these categories and they are referred to as the 'information group'. In view of the small numbers, tests of statistical significance were not carried out and descriptive statistics only are presented.

\section{Findings}

The mothers

Demographic and psychiatric data about all the mothers are summarised in Table 1 , together with information about carers during the mother's admission.

The mothers in the two groups were similar in terms of age and marital status, and the greater number of Asian women in the information group was mainly a reflection of language difficulties. The higher proportion of mothers with a diagnosis of psychosis in the information group mainly reflects those who could not be interviewed due to disturbed mental state. A history of
Table 1. Maternal demographic and psychiatric data, and carers during mother's admission

\begin{tabular}{lcc}
\hline & $\begin{array}{c}\text { Interview } \\
\text { group }\end{array}$ & $\begin{array}{c}\text { Information } \\
\text { group }\end{array}$ \\
\hline Maternal age & 7 & 6 \\
$<30$ & 15 & 17 \\
$30-39$ & 4 & 2 \\
$40+$ & 17 & 15 \\
Marital status & 9 & 10 \\
$\quad$ Married & & \\
Lone & 15 & 10 \\
Ethnicity & 6 & 11 \\
$\quad$ Caucasian & 5 & 4 \\
Asian & & \\
Other & 11 & 19 \\
Diagnosis & 15 & 6 \\
Psychosis & & \\
$\quad$ Non-psychotic & 8 & 14 \\
Chronic psychiatric disorder' \\
$\quad$ Psychosis & 4 & 0 \\
Non-psychotic & & \\
Carer & 23 & 3 \\
$\quad$ Father/family & 3 & 22 \\
Non-family & & \\
\hline
\end{tabular}

1. Chronic psychiatric disorder-past admission(s)+ current admission longer than four weeks.

previous psychiatric admissions together with current admission lasting more than four weeks was taken as indicating chronic psychiatric disorder. This combination was found for 12 mothers in the interview group and for 14 mothers in the information group. Some admissions were very short and some of these were missed completely. Others were long-five mothers from each group were in hospital for more than three months, and one from the interview group was an in-patient for over a year. Most children were cared for by their father or other family members. One child was cared for by a friend of the mother, three were accommodated by social services and two babies were cared for by staff on an acute psychiatric ward.

\section{Children and child care arrangements}

Fuller information about care arrangements was only available for the interview group. The combined mothers in this group usually cared for a total of 53 children. For 12 of these children. care arrangements included moving house, eight of this sub-group being children of lone mothers. Information about children who did or did not move house by age and by mother's marital status is shown in Table 2.

In addition to the house moves for eight of the 13 children of lone mothers, these eight and two others were cared for by someone with whom they had not had frequent contact previously. 
Table 2. Children who moved house (by age of children and marital status of mother)

\begin{tabular}{llllll}
\hline & \multicolumn{2}{l}{ Children of married mothers } & \multicolumn{2}{l}{ Children of lone mothers } \\
\cline { 2 - 3 } \cline { 5 - 6 } Age of child & Total & 3 & Number moved house & Total & Number moved house \\
\hline $0-4$ & 18 & 1 & 5 & 1 \\
$5-10$ & 15 & 0 & 5 & 4 \\
$11-16$ & 7 & 4 & 13 & 4 \\
All & 40 & & &
\end{tabular}

A number of carers had to take time off work and one father had given up his job. Few mothers had been working prior to admission due to a combination of factors including psychiatric illness, ethnicity and high levels of unemployment in the area. No formal attempt was made to check the recording of child information in medical notes but in the course of scanning these for psychiatric history, it was clear that there was little or no information about child care arrangements unless social services were involved.

\section{Mothers' contact with children during admission}

Most mothers saw their children regularly during the admission. This contact was often on the ward (a few mothers avoided this because of concern about the children) but also at home during periods of leave before discharge. None of the mothers reported negative attitudes on the part of nursing staff towards children visiting. Some of the wards had side rooms which could be used during visiting times, but on other wards all contact with visitors had to take place in large public areas or in the hospital grounds. None of the wards provided any toys or games suitable for children.

\section{Comment}

The main findings of this study are that for the interview group ( 26 mothers, 53 children) nearly a quarter of the children had to move house, and that for half the mothers in the whole group (26 out of 51) there was evidence of chronic psychiatric disorder. An incidental finding was that many mothers were visited in hospital by their children.

The numbers are small and there was some bias towards inclusion of mothers with more severe psychiatric disorder with a number of brief admissions being missed altogether. The lack of interview data from half the total sample is a further limitation. The main reasons for this were disturbed mental state, which persisted for long periods in a few cases, and language limitation related to ethnicity. The overall ethnic composition of the group was representative of the usual psychiatric in-patient population for the wards concerned.

The lives of some children were considerably disrupted after maternal psychiatric admission. Greater change was experienced by the children of lone parents, many of whom had to move house and were cared for by someone with whom they had not previously had frequent contact. These findings echo those of much earlier research in Massachusetts (Ekdahl et al, 1962) which described the experience of children after a parent was hospitalised for mental illness or tuberculosis.

The finding that for half the mothers there was evidence of chronic psychiatric disorder is also of concern. Epidemiological studies have shown increased risk of psychiatric disorder in the children of parents with psychiatric disorder with strongest correlation with factors such as parental personality disorder rather than psychosis (Rutter \& Quinton, 1984). However, there is little doubt that the quality of the mother-child relationship is likely to be affected by maternal psychiatric disorder. Many aspects of this are discussed by various authors in Gopfert et al (1996), together with suggested interventions for benefit of both mother and child.

Unfortunately such interventions with mothers often do not happen due to pressures on psychiatric services, particularly in urban areas, and because of poor liaison between adult and child services. These problems have been highlighted by Hatfield et al (1997) in their audit of Mental Health Act assessments carried out by approved social workers, also by Stormont et al (1997) in their survey of psychiatric in-patients who were parents.

One route towards more effective interventions on behalf of children whose mothers have psychiatric disorders could be the Care Programme Approach but a major hurdle is continuing lack of awareness of patients as parents. Information about children was usually well known to nursing staff contacted for this study but such information only seems to impinge on clinical decision-making when social workers are already involved with a child. In this respect little seems to have changed since an earlier conclusion 
that family information is not considered of much importance in the management of acute psychiatric admissions (Cottrell, 1989). However, it is to be hoped that the appearance of recent publications on aspects of parental psychiatric disorder may be an indication of changing attitudes and practice.

One practical reason for lack of awareness of patients' children is that they are generally 'invisible' to senior clinicians and managers who are rarely on wards at visiting times. This study found that children of patients are frequent visitors on some acute psychiatric wards despite very inadequate provision for them. Wider recognition of child visiting could lead to simple but imaginative adaptations such as rooms being set aside for family visits and the provision of some toys and games.

\section{References}

COTTRELL, D. (1989) Family therapy influences on general psychiatry. British Journal of Psychiatry, 130. 201-210.
EKDAHL, M. C.. RicE, E. P. \& SCHMiDT, M. (1962) Children of parents hospitalised for mental illness. American Joumal of Public Health, 52, 428-435.

Gopfert, M.. WEBster, J. \& SEeman, M. V. (eds) (1996) Parental Psychiatric Disorder. Cambridge: Cambridge University Press.

HATFIELD, B., WEBSTER, J. \& MOHAMED, H. (1997) Psychiatric emergencies: assessing parents of dependent children. Psychiatric Bulletin, 21, 19-22.

OATES, M. (1997) Patients as parents: the risk to children. British Journal of Psychiatry, 170 (suppl. 32). 22-27.

RUTTER, M. \& QUINTON. D. (1984) Parental psychlatric disorder: effects on children. Psychological Medicine. 14. 853-880.

Stormont, F. Craig, T., AKakan, Z., et al (1997) Concerns about the children of psychlatric inpatients: what parents say. Psychiatric Bulletin, 21, 495-497.

*Valerie Hawes, Specialist Registrar, Forensic Psychiatry Service, Box 175, Addenbrooke's Hospital, Hills Road, Cambridge CB2 290 and David Cottrell, Professor, Academic Unit of Child and Adolescent Mental Health, School of Medicine, University of Leeds, Leeds

*Correspondence

\title{
Reducing the time you and your patients wait
}

\author{
Kadiyali M. Srivatsa and Danny Allen
}

\begin{abstract}
Aims and methods in an attempt to reduce patient non-attendance at first appointments, consultant referrals were handled differentially over three years. From referral letters some patients were referred elsewhere, some sent appointments and some invited to make appointments.

Results There was a reduction in patients who did not attend an appointment and an increase in the proportion of patients, not referred elsewhere who were seen.

Clinical implications This system reduces consultant waiting time in clinics and the interval before a patient is seen.

Traditionally, patients referred to a psychiatrist are sent appointments; some do not attend. These 'empty slots' can waste a lot of time and significantly increase the waiting list, with
\end{abstract}

attendant problems of morbidity, hospital admission and potential contractual difficulties. One study in a community setting indicated a 'no-show' rate of between 26 and 50\% (Chen. 1991). Another study showed that there was an association with length of wait for an appointment, previous treatment, chief complaint and source of referral (Carpenter et al, 1981). A study by psychologists indicated that the nonattendance rate for subsequent appointments dropped once the initial appointment had been kept (Weighill et al, 1983). Various methods have been tried to reduce missed appointments, such as telephone reminders (Hochstadt \& Trybula, 1980; Carr, 1985) and completing behavioural check-lists (Deane, 1991) but with only limited success. Sparr et al (1993) found that patients with post-traumatic stress disorder and substance misuse were significantly 